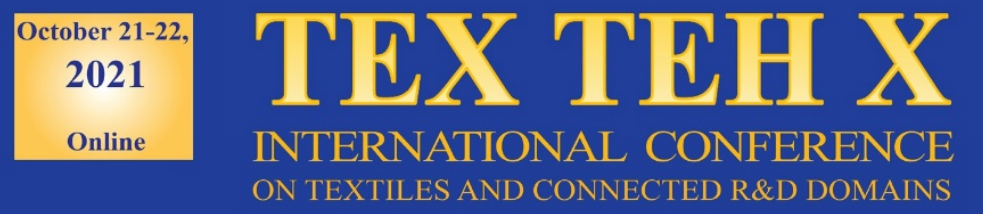

\title{
ANALYSIS OF THE MECHANICAL PROPERTIES OF SOME HIGH- TECH YARNS WITH DIFFERENT FUNCTIONS
}

\author{
DOI: $10.35530 /$ TT.2021.38
}

\section{T. Sârbu, C.E. Stroe}

R\&D Department - Textile Materials and Processes Engineering, National Research and Development Institute for Textiles and Leather, Romania (e-mail: teodor.sarbu@incdtp.ro, cristina.stroe@incdtp.ro)

\begin{abstract}
We live in a knowledge-based society, which is facing an increasing impact of science and technology on all aspects of life through products, services and consumer needs. In the future, society will be oriented towards the individual and his needs, which will be more and more complex and varied. The present paper comparatively presents a series of variants of cotton fibre yarns: made of blended cotton fibres with ultra-high molecular weight polyethylene fibres; yarns of cotton fibres blended with regenerated cellulose fibres, that were functionalized with $\mathrm{Ag}$ ions and yarns obtained from fibre blends of recycled organic cotton, virgin cotton with recovered cotton fibres in order to observe their mechanical potential. The built-in functionalities allow their use in areas such as healthcare and hygiene, sports and leisure activities. The recovery of textile waste in a circular approach and the transition to a circular economy is an important direction for research. The repercussions that the consumption of raw materials in the textile industry has, on the environment, as well as on sustainability, determine us to reason in a judicious way when we select the different materials that we use in making the products.
\end{abstract}

Keywords: eco nanotechnologies, functional textiles, high-tech yarns

\section{INTRODUCTION}

Functional textiles are an interdisciplinary field that incorporates science, technology and design, and its future lies in the potential to combine different technologies [1].

Functional cotton textiles blended with cellulose that incorporate silver ions, through their antimicrobial properties lead to improved quality of life and contribute to significant savings for the health budget [2].

For the production of advanced textile materials, the research methodology includes innovative techniques for functionalizing the materials by:

- high-tech yarn processing, with nano and micro functionalization through classic, flexible, ecological technologies;

- incorporation of passive and / or active interactive elements in textile structures;

- eco-nanotechnologies such as electroplating and 3D printing;

- closing the value chain through eco-innovative waste processing technologies.

The most frequently used yarns for making clothing items are:

- $100 \%$ cotton yarns;

- cotton yarns blended with cellulose;

- recycled cotton yarns.

The main purpose of yarn functionalization is to create the basic relationships 
between properties and effects in fibrous materials, reagents, additives, reactive media and reaction parameters.

With modern finishing, coating and treatment technologies, innovative and highly functional technical textiles are developed for a wide range of applications, including power generation, textile architecture, medical materials, conductive / sensor materials or high temperature textile protection [3].

These yarns can be a set of variants that underlie the generation of an experimental matrix of woven and / or knits with comfort and performance functionalities and recovered fibre elements in the current context of research.

\section{MATERIALS AND METHODS}

\subsection{Materials}

High-tech high molecular weight polyethylene fibre (UHMWPE) offers maximum strength with minimum specific mass.

Regenerated cellulose fibre was obtained through an eco-friendly technology, and by adding silver (Ag) ions to the polymeric mass before spinning, remarkable antibacterial properties are obtained. This type of functionalisation also offers a longer time to use the yarns.

The yarns used in this research, had the following characteristics:

2 variants of cotton spun yarns:

- Variant 1 (V1), tex: 23,05x2 - 100\% cotton fibres;

- Variant 2 (V2), tex: 19x2 - blend of 80\% cotton fibres and 18\% regenerated cellulose fibres functionalized mass with $2 \%$ Ag ions particles.

$>3$ variants of spun yarns from a blend of cotton fibres with different percentages of UHMWPE fibres:

- Variant 3 (V3), tex: 30x1 - 98\% cotton and 2\% UHMWPE;

- Variant 4 (V4), tex: 30x1 - 95\% cotton and 5\% UHMWPE;

- Variant 5 (V5), tex: 30x1 - 90\% cotton and 10\% UHMWPE.

$>4$ variants of yarns made of recycled organic cotton, virgin cotton and recovered cotton fibres:

- Variant 6 (V6), tex: 21,42x2 - thread R-EARTH / E 50, 50\% recycled cotton + 50\% organic cotton (Hilaturas Ferre);

- Variant 7 (V7), tex: 33,06x2 - thread R-EARTH / E 50, 50\% recycled cotton + 50\% organic cotton (Hilaturas Ferre);

- Variant 8 (V8), tex: 63,52x2 - R-Jeans / J 30 yarn: 27\% recycled cotton +70 \% organic cotton $+3 \%$ other recycled yarn (Hilaturas Ferre);

- Variant 9 (V9), tex: 63,06x1 - thread R-Jeans / J 30: 27\% recycled cotton $+70 \%$ organic cotton $+3 \%$ other recycled yarn (Hilaturas Ferre).

The two types of fibres from regenerated cellulose and UHMWPE, are distinguished by different properties, exemplified in table 1 .

Table 1. Lyocell and Dyneema fibres properties [4-6]

\begin{tabular}{|c|c|}
\hline Lyocell fibre properties & Dyneema fibre properties \\
\hline High tensile strength (2X rayon dry / 3X rayon wet) & $\begin{array}{c}\text { Extremely strong (up to 15 times stronger than steel } \\
\text { and up to 40\% stronger than aramid fibres) }\end{array}$ \\
\hline Highly absorbent & Cut and tear resistance \\
\hline $\begin{array}{c}\text { Higher water vapour permeability than cotton which } \\
\text { means that garments are comfortably cool to wear }\end{array}$ & Low elongation \\
\hline High wet and dry modulus & Low density \\
\hline
\end{tabular}




\begin{tabular}{|c|c|}
\hline Easily dyeable to strong color-fast shades & Low coefficient of friction \\
\hline $\begin{array}{c}\text { Stable at high temperatures (above } 170^{\circ} \mathrm{C} \text { the fibre } \\
\text { will start to lose strength gradually) }\end{array}$ & High abrasion resistance \\
\hline $\begin{array}{c}\text { It biodegrades completely during biological } \\
\text { treatment, such as burial or anaerobic digestion }\end{array}$ & High pliability \\
\hline- & Soft as silk \\
\hline- & Hydrophobicity \\
\hline
\end{tabular}

\subsection{Methods}

The tests on the yarns were performed on the equipment from the testing laboratories, INCDTP accredited by Romanian Accreditation Association (RENAR). determined:

During the research, the following physical and mechanical properties were

- length density (tex); C.V. (\%);

- torsion/ twist (no. tors./m); C.V. (\%);

- breaking tenacity $(\mathrm{N})$; C.V. (\%);

- elongation at break (\%); C.V. (\%).

\section{RESULTS AND DISCUSSIONS}

The yarns made of $100 \%$ cotton and those made of the blend cotton and regenerated cellulose with Ag ions were analysed to compare their properties with the high-performance yarns, and those with content of recovered fibres from waste, in order to highlight the mechanical potential and to identify areas of use. Tables 2, 3 and 4 show the results of the tests performed for the three categories of yarns.

Table 2. Yarns length density

\begin{tabular}{|c|c|c|c|c|c|c|c|c|c|}
\hline Variants & V1 & V2 & V3 & V4 & V5 & V6 & V7 & V8 & V9 \\
\hline Length density (tex) & $23.05 \times 2$ & $19 \times 2$ & $30 \times 1$ & $30 \times 1$ & $30 \times 1$ & $21.42 \times 2$ & $33.06 \times 2$ & $63.52 \times 2$ & $63.06 \times 1$ \\
\hline CV (\%) & 10.21 & 5.79 & 9.23 & 5.31 & 5.86 & 3.38 & 5.41 & 4.4 & 3.38 \\
\hline
\end{tabular}

Table 3. Breaking tenacity of cotton yarns

\begin{tabular}{|c|c|c|c|c|}
\hline Determination & \multicolumn{2}{|c|}{ Breaking tenacity (N/tex) } & \multicolumn{2}{c|}{ Elongation at break (\%) } \\
\hline Variants, tex & V1 23.05x2 & V2 19x2 & V1 23.05x2 & V2 19x2 \\
\hline Average & 0.1810 & 0.1476 & 8.4800 & 8.6500 \\
\hline Standard deviation & 0.0079 & 0.1315 & 0.4237 & 0.5580 \\
\hline CV (\%) & 0.0694 & 0.8909 & 4.995 & 6.4500 \\
\hline
\end{tabular}

The breaking tenacity of cotton and regenerated cellulose yarn is close to that of $100 \%$ cotton yarn, but in relation to the lower fineness, this aspect demonstrating the ability of this yarn to withstand mechanical stress (figure 1). 


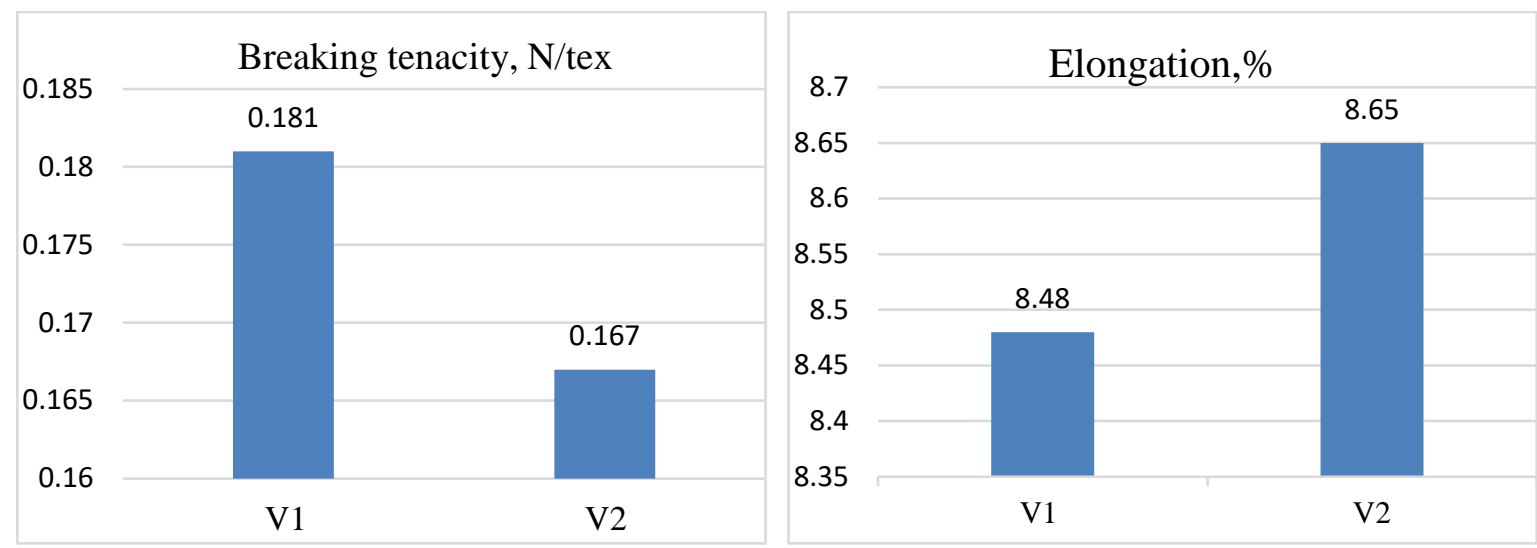

Figure 1. Breaking tenacity (N/tex) and elongation at break (\%) for cotton yarns

Table 4. Breaking tenacity of yarns made of cotton and UHMWPE fibres

\begin{tabular}{|c|c|c|c|c|c|c|}
\hline Determination & \multicolumn{3}{|c|}{ Breaking tenacity (N/tex) } & \multicolumn{3}{c|}{ Elongation at break (\%) } \\
\hline Variants & $\begin{array}{c}\text { V3 } \\
\text { 30x1; } \%\end{array}$ & $\begin{array}{c}\text { V4 } \\
\text { 30x1; } \%\end{array}$ & $\begin{array}{c}\text { V5 } \\
\text { 30x1; } 10 \%\end{array}$ & $\begin{array}{c}\text { V3 } \\
30 \times 1 ; 2 \%\end{array}$ & $\begin{array}{c}\text { V4 } \\
\text { 30x1; 5\% }\end{array}$ & $\begin{array}{c}\text { V5 } \\
30 \times 1 ; 10 \%\end{array}$ \\
\hline Average & 0.1670 & 0.1810 & 0.1916 & 8.6500 & 8.48 & 8.2900 \\
\hline $\begin{array}{l}\text { Standard } \\
\text { deviation }\end{array}$ & 0.0297 & 0.0079 & 0.1111 & 0.558 & 0.4237 & 0.4270 \\
\hline CV (\%) & 0.1778 & 0.0694 & 0.1019 & 6.4500 & 4.9950 & 5.1500 \\
\hline
\end{tabular}

Following the determinations, it was observed that the V5 yarn has the highest breaking tenacity; elongation at break for yarns containing decreases in correlation with increasing the percentage of UHMWPE fibres, demonstrating the ability of this type of yarn to resist at mechanical stresses. Only a content of 5 and 10\% UHMWPE brings improvements in the breaking tenacity of the yarns (table 4).
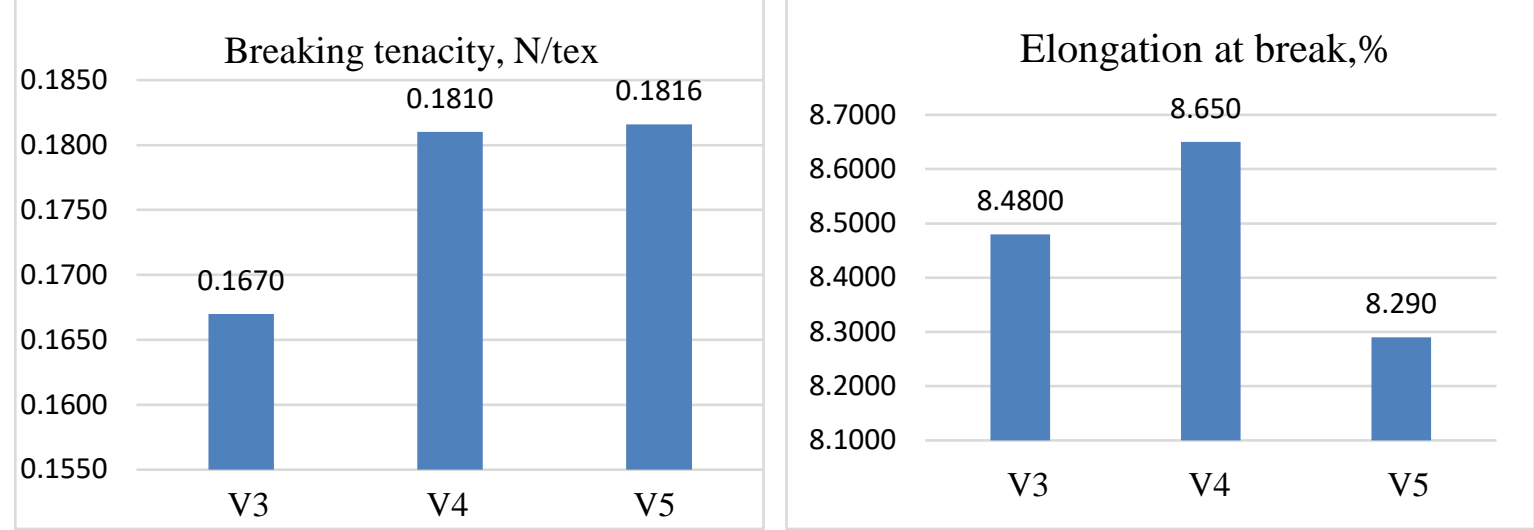

Figure 2. Breaking tenacity (N/tex) and elongation at break (\%) for cotton with UHMWPE yarns

The lowest tenacity values were registered in the case of yarns with a percentage of recovered fibres, with the exception of V9, with a higher breaking tenacity even than those with $2 \%, 5 \%, 10 \%$ of UHMWPE fibres and the V7 variant has the breaking tenacity close to the results of cotton-UHMWPE yarns. 
Table 5. Breaking tenacity of yarns made of recycled and organic cotton fibres

\begin{tabular}{|c|c|c|c|c|c|c|c|c|}
\hline Determination & \multicolumn{3}{|c|}{ Breaking tenacity (N/tex) } & \multicolumn{4}{c|}{ Elongation at break (\%) } \\
\hline Variants, tex & V6 & V7 & V8 & V9 & V6 & V7 & V8 & V9 \\
& $21.42 \mathrm{x}$ & $33.06 \mathrm{x}$ & $63.52 \mathrm{x}$ & $63.06 \mathrm{x}$ & $21.42 \mathrm{x}$ & $33.06 \mathrm{x}$ & $63.52 \mathrm{x}$ & $63.06 \mathrm{x}$ \\
& 2 & 2 & 2 & 1 & 2 & 2 & 2 & 1 \\
\hline Average & 0.0766 & 0.1020 & 0.0800 & 0.3480 & 4.7850 & 9.1400 & 6.4800 & 9.6500 \\
\hline $\begin{array}{c}\text { Standard } \\
\text { deviation }\end{array}$ & 0.0063 & 0.0070 & 0.0061 & 0.0202 & 0.5280 & 0.7960 & 0.3926 & 0.5150 \\
\hline CV (\%) & 8.1600 & 6.8500 & 7.6400 & 5.8100 & 11.0400 & 8.7100 & 6.0600 & 5.3400 \\
\hline
\end{tabular}
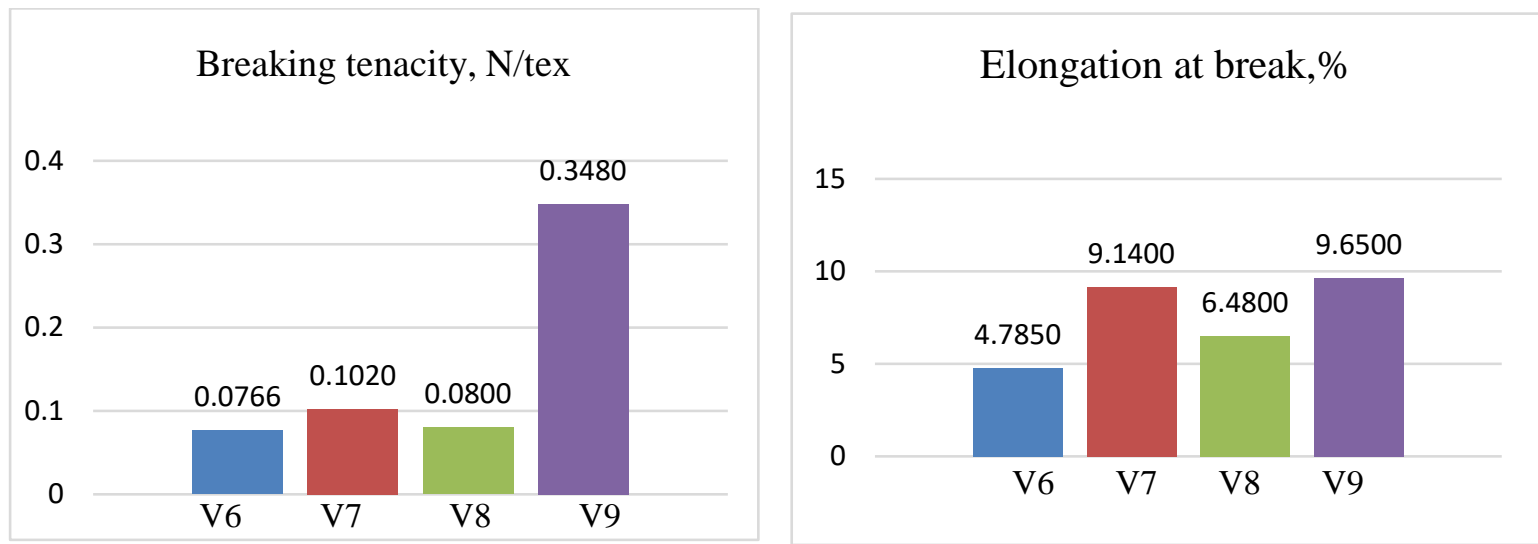

Figure 3. Breaking tenacity (N/tex) and Elongation at break (\%) for recycled organic cotton yarns

Therefore, due to the superior resistance, these types of yarns from regenerated fibre content can be used in favour of the synthetic ones, supporting the concept of circular economy and sustainability.

\section{CONCLUSIONS}

It is recommended that the performance yarns be used in a judicious manner.

Yarns with 2\% UHMWPE can be used for making clothing or non-clothing products entirely in relation to the textile surface.

The increase of the percentage imposes the realization of clothing or non-clothing products of modulated type, and the yarns with content of $5 \%$ or $10 \%$ UHMWPE to correspond exactly to the areas where it is necessary to manifest its performance.

The yarns may be used with a suitable design, including in combination with yarns containing a certain percentage of recovered fibres.

The values of the mechanical potential of yarns obtained from the blending of fibrous organic cotton with recovered cotton fibres can be compared even with conventional yarns of virgin fibres of the same fineness.

Also, the results of breaking resistance, obtained in laboratory, recommend the use of these types of yarns both in warp and weft, given that the yarns obtained from waste are mainly used in weft or in the production of low-strength products.

\section{ACKNOWLEDGEMENTS}

The results presented in this paper were obtained in the projects: 
- PN 19170303 "Macro-meso-micro advanced materials for health and quality of life improvement (AkSuTex).

- LIFE17 ENV/ES/000290 “A 100\% rel circular economy process for vegane-organicrecycled footwear".

\section{REFERENCES}

[1] European Environment Agency, Circular by design - Products in the circular economy, ISSN 1977-8449, 2017

[2] Piscis, V., Circular Design Project, 2021, Available at: https://vesicapiscisfootwear.com/en/content/19-RECYCLABLE [Accessed on June 2021]

[3] Tatusa, H., Glin, O.P., Makiko, T., New millenium fibres - applied examples of high tech fiber, The Textile Institute Woodhead Publishing Limited, 2005

[4] Engineered fibres technology, Tencel ${ }^{\circledR}$ lyocell short cut fiber, Available at: http://www.eftfibers.com/prod_lyocell.php [Accessed on June 2021]

[5] Parul, G., Pankaj, G., Singh, S.S.J., Lyocell Properties and applications, In: Man-Made Textiles in India, 2002

[6] FibrXL smart performance fibres Dyneema ${ }^{\circledR}$, Available at: https://fibrxl.com/fibrxlperformance/fibers/dyneema/ [Accessed on June 2021] 